\title{
Family- and school-based predictors of energy balance-related behaviours in children: a 6-year longitudinal study
}

\author{
Maiité Verloigne ${ }^{1, *}$, Wendy Van Lippevelde ${ }^{2}$, Lea Maes ${ }^{2}$, Johannes Brug ${ }^{3}$ and \\ Ilse De Bourdeaudhuij ${ }^{1}$ \\ 'Department of Movement and Sport Sciences, Faculty of Medicine and Health Sciences, Ghent University, \\ Watersportlaan 2, B-9000 Ghent, Belgium: ${ }^{2}$ Department of Public Health, Ghent University, Ghent, Belgium: \\ ${ }^{3}$ Department of Epidemiology \& Biostatistics and EMGO Institute for Health and Care Research, VU University \\ Medical Center, Amsterdam, The Netherlands
}

Submitted 27 January 2012: Final revision received 22 June 2012: Accepted 31 July 2012: First published online 19 September 2012

\begin{abstract}
Objective: To examine family- and school-based predictors of breakfast consumption, soft drink consumption and physical activity (PA) and moderating effects of gender and socio-economic status (SES).

Design: Longitudinal study (6-year follow-up), including a questionnaire about dietary and activity behaviour.

Setting: Fifty-nine Flemish elementary schools.

Subjects: Seven hundred and twenty-seven children (51.9\% girls, 51.9\% high SES, mean age $9 \cdot 9($ SD $0 \cdot 4)$ years at baseline).

Results: Having breakfast together with parents $(P<0.001)$ at age 10 years related to more days of eating breakfast at age 16 years. More parental soft drink consumption $(P=0 \cdot 04)$, less soft drink availability at home $(P<0 \cdot 001)$ and less parental permissiveness (children received soft drinks from their parents whenever they asked for it and children could take soft drinks whenever they wanted; $P=0.02$ and $P=0.001$, respectively) at age 10 years related to less soft drink consumption at age 16 years. A more positive parental attitude towards PA $(P=0 \cdot 009)$, more parental encouragement $(P=0 \cdot 002)$ and a higher rating of PA's benefit 'relaxing' $(P<0 \cdot 001)$ at age 10 years related to more PA at age 16 years. Gender and SES did not significantly moderate any of the associations.

Conclusions: Only parental factors at age 10 years were associated with breakfast consumption, soft drink consumption and PA at age 16 years. An intervention programme at age 10 years with a strong focus on the modifiable parental factors might lead to healthy behaviour in the long term.
\end{abstract}

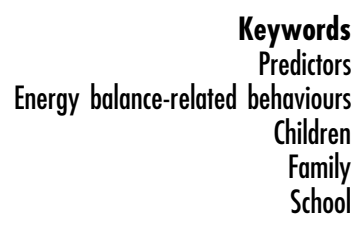

The high prevalence of overweight and obesity among children urges the need to develop effective programmes to prevent obesity. A first step is to identify the energy balance-related behaviours (EBRB) that are related to overweight and obesity. The next step is then to provide theory-based empirical evidence on the most important and modifiable determinants, correlates and predictors of those EBRB that can be targeted in an obesity prevention programme $^{(1)}$. Preferably, a theoretical framework should guide the research to gain insight into the complexity of the factors that are associated with EBRB. Kremers et $a l^{(2)}$ have proposed the Environmental Research framework for weight Gain prevention (EnRG framework), which integrates environmental factors (inspired by the ANalysis Grid for Environments Linked to Obesity (ANGELO) framework) ${ }^{(3)}$ with more psychological or 'cognitive' factors (based on insights from the Theory of Planned Behaviour ${ }^{(4)}$ ) and identifies personal and behavioural moderators to understand the processes that underlie EBRB. According to the framework, environmental factors can have a direct impact on the behaviours or can be mediated by the cognitive factors. Specifically for children, it is important to focus on family environmental factors, because research has indicated that parents (and not peers) have the most impact on children's EBRB by influencing both the physical and social environment of their children ${ }^{(5-7)}$ and it has been argued that intervention strategies for children need a major focus on the family context and parental involvement ${ }^{(8)}$. Next to the family environment, the school environment can be considered important as well, since schools have the capacity to provide several opportunities to practise healthy dietary behaviours and to engage in physical activity (PA) ${ }^{(9-12)}$. Moreover, the majority of children can be easily accessed through schools and children spend a significant amount of time at school. Thus, a better understanding of the 
specific family- and school-based factors of the most important EBRB in youngsters will enable the development of an effective intervention programme.

A recent systematic review aimed at identifying familyand school-based correlates of four EBRB (PA, sedentary behaviour, breakfast and soft drink consumption) in children in the transition from childhood to adolescence (10-12 years old $)^{(13)}$, i.e. an age group where children gain increasing autonomy and decision-making power ${ }^{(14)}$. The results suggested the important role of parental role modelling in influencing schoolchildren's EBRB (e.g. parental behaviour was related to the child's behaviour for all EBRB) and also indicated the general lack of published research to identify school-based correlates of EBRB in 10- to 12-year-olds. Further, it was concluded that more and better-designed research is needed on the parental and school-based factors related to EBRB in schoolchildren, as $75 \%$ of the reviewed studies had a cross-sectional design. Cross-sectional studies can only establish associations, and not prediction or causation, suggesting that longitudinal studies are preferred. Results from a longitudinal study could inform an intervention programme for 10- to 12-yearold children that consequently might have positive effects on children's behaviour in the long term. Moreover, only three out of nineteen longitudinal studies included in the review were conducted in Europe ${ }^{(10,15,16)}$, and it is doubtful whether evidence regarding correlates and predictors of EBRB from non-European populations can be applied within Europe ${ }^{(17)}$.

Therefore, the first aim of the present study was to investigate which family and school environmental factors at age 10 years can predict EBRB at age 16 years in a Flemish sample. It is important to investigate predictors of several EBRB to focus on energy intake as well as expenditure, since both contribute to the development or prevention of overweight and obesity. Previous research has provided convincing or at least strongly suggestive evidence that breakfast consumption ${ }^{(18)}$, soft drink consumption ${ }^{(18-21)}$ and $\mathrm{PA}^{(22)}$ are associated with overweight and obesity in childhood and adolescence. Moreover, lack of physical activities, breakfast skipping and high intakes of sugary drinks are highly prevalent in children on the brink of adolescence across Europe ${ }^{(23)}$. Therefore, the present study investigated predictors of breakfast consumption, soft drink consumption and PA.

The second study aim was to examine the moderating effects of gender and socio-economic status (SES) on the association of family and school environmental factors with EBRB. Earlier research suggests that these behaviours may be influenced or predicted by different factors in girls and boys ${ }^{(24-27)}$. For example, two previous studies have found that parental PA behaviour was only related to PA behaviour of boys, not girls ${ }^{(24,25)}$. To our knowledge, no previous studies have examined SES as a potential moderator of correlates of EBRB in early adolescence. However, the socio-economic inequalities in health behaviour ${ }^{(28)}$ could imply that the behaviour of children from low-SES $v$. high-SES backgrounds is affected by different factors as well.

\section{Experimental methods}

\section{Procedure}

Data were used from the Longitudinal Eating and Activity study (LEA study) ${ }^{(29)}$. One hundred elementary schools from two Flemish regions were randomly selected from the official list of the Flemish Government in 2002. The principals were sent a recruitment letter and afterwards contacted by telephone. Fifty-nine principals agreed to cooperate in the study. All children of the 5th grade (10-year-olds) in these fifty-nine schools were invited to participate in the study ( $n$ 1957) in October-December 2002. Informed consent to let their children participate was received from 1725 parents (88.1\%). The children completed a self-administered questionnaire on eating habits and PA, demographic variables and possible familyand school-based predictors in the classroom under the supervision of one researcher and their classroom teacher. In total, 1670 child questionnaires were collected. Every child was also given a questionnaire to be completed by one of the parents. This parent questionnaire collected data on sociodemographic characteristics, parenting style, parenting practices and family-based predictors of health behaviours. Response percentage and informed consent of the parents was $82.5 \%$, which resulted in 1614 child-parent couples of usable questionnaires. In 2004, all children left primary school and entered different secondary schools making classroom based administration of questionnaires impossible. In the autumn of 2008, all children were again contacted by a letter sent to their home addresses. The envelope also contained a questionnaire and a pre-stamped envelope to send the questionnaire back via regular mail. A total of 727 questionnaires were received that could be matched with the data of $2002(45 \cdot 0 \%)$. Ethical approval for the LEA study was received from Ghent University Hospital.

\section{Measures}

\section{Demographic variables}

Self-reported weight and height were used to calculate BMI $\left(\mathrm{kg} / \mathrm{m}^{2}\right)$. Parental education level was used as a proxy for SES. The highest level of education of the parent who filled in the questionnaire in 2002 was used as a measure of SES, dichotomized into 'higher education' (college or university) or 'no higher education' (no education, primary or secondary school).

\section{Behaviour measures}

The items to assess breakfast and soft drink consumption are described in Table 1. The food frequency questions were found to have sufficient reliability (weighted $\boldsymbol{\kappa}=0 \cdot 66$ ) 
Table 1 Overview of the dietary behaviour measures and family and school environmental variables

\begin{tabular}{|c|c|c|}
\hline Behaviour measures & Item (child questionnaire) & Response category \\
\hline Breakfast consumption & $\begin{array}{l}\text { 'How often do you eat breakfast during the week?' } \\
\text { 'How often do you eat breakfast during the weekend?' }\end{array}$ & $\begin{array}{l}\text { Answers from } 0 \text { to } 5 \mathrm{~d} \\
\text { Answers from } 0 \text { to } 2 \mathrm{~d} \\
\text { Summing up both items to assess total frequency per week }\end{array}$ \\
\hline Soft drink consumption & $\begin{array}{l}\text { 'How many days per week do you usually drink cola or other sugar- } \\
\text { sweetened beverages?' }\end{array}$ & $\begin{array}{l}\text { 7-point scale }(1=\text { never; } 2=<1 \mathrm{~d} / \text { week; } 3=1 \mathrm{~d} / \text { week; } \\
4=2-4 \mathrm{~d} / \text { week; } 5=5-6 \mathrm{~d} / \text { week; } 6=\text { every day; } 7=\text { every day, } \\
\text { more than once daily })\end{array}$ \\
\hline Family environmental predictor & Item (child/parent questionnaire) & Response category \\
\hline \multicolumn{3}{|l|}{ Sociocultural (general) } \\
\hline Good student according to parent? & $\begin{array}{l}\text { 'What do you think about the school results of your son/daughter in } \\
\text { comparison to his/her classmates?' (parent) }\end{array}$ & $\begin{array}{l}\text { 4-point scale }(1=\text { below average; } 2=\text { average student; } 3=\text { good } \\
\text { student; } 4=\text { very good student })\end{array}$ \\
\hline BMI parent & Height and weight (parent) & {$[$ Weight $(\mathrm{kg})] /[\text { height }(\mathrm{m})]^{2}$} \\
\hline $\begin{array}{l}\text { Single-parent household } \\
\text { Sociocultural (related to BC) }\end{array}$ & 'Are you a single parent?' (parent) & $0=$ yes; $1=$ no \\
\hline \multicolumn{3}{|l|}{ Sociocultural (related to BC) } \\
\hline Breakfast together & $\begin{array}{l}\text { 'Do you or your partner have breakfast TOGETHER with your child?' } \\
\text { (parent) }\end{array}$ & $\begin{array}{l}5 \text {-point scale }(1=\text { (almost) never; } 2=\text { less than half of week; } \\
3=\text { approximately half of week; } 4=\text { more than half of week; } \\
5=\text { (almost) every day) }\end{array}$ \\
\hline \multicolumn{3}{|l|}{ Physical (related to SDC) } \\
\hline Soft drink consumption availability & 'Are soft drinks available at home?' (parent) & $\begin{array}{l}\text { 3-point scale }(1=\text { seldom or never; } 2=\text { sometimes; } 3=\text { (almost }) \\
\text { always) }\end{array}$ \\
\hline \multicolumn{3}{|l|}{ Sociocultural (related to SDC) } \\
\hline Soft drink consumption parents & 'How many days per week do you drink soft drinks?' (parent) & $\begin{array}{l}\text { 7-point scale }(1=\text { never; } 2=<1 \mathrm{~d} / \text { week or seldom; } 3=1 \mathrm{~d} / \text { week; } \\
4=2-4 \mathrm{~d} / \text { week; } 5=5-6 \mathrm{~d} / \text { week; } 6=\text { every day; } 7=\text { every day, } \\
\text { more than once daily })\end{array}$ \\
\hline \multicolumn{3}{|l|}{ Political (related to SDC) } \\
\hline Soft drink consumption parenting 1 & 'I don’t drink soft drinks because of my child’s presence’ (parent) & $\begin{array}{l}\text { 5-point scale }(1=\text { never; } 2=\text { almost never; } 3=\text { sometimes; } \\
4=\text { almost always; } 5=\text { always })\end{array}$ \\
\hline Soft drink consumption parenting 2 & 'I give my child soft drinks whenever he/she asks for it' (parent) & $\begin{array}{l}5 \text {-point scale }(1=\text { always; } 2=\text { almost always; } 3=\text { sometimes; } \\
4=\text { almost never; } 5=\text { never })\end{array}$ \\
\hline Soft drink consumption parenting 3 & 'My child can drink soft drinks whenever he/she wants' (parent) & $\begin{array}{l}\text { 5-point scale }(1=\text { always; } 2=\text { almost always; } 3=\text { sometimes; } \\
\quad 4=\text { almost never; } 5=\text { never })\end{array}$ \\
\hline \multicolumn{3}{|l|}{ Sociocultural (related to PA) } \\
\hline Physical activity cycling together & $\begin{array}{l}\text { 'How many hours and minutes per week do you cycle TOGETHER } \\
\text { with your child?' (parent) }\end{array}$ & $\ldots$ hours, ... minutes \\
\hline Physical activity walking together & $\begin{array}{l}\text { 'How many hours and minutes per week do you walk TOGETHER with } \\
\text { your child?' (parent) }\end{array}$ & $\ldots$ hours, ... minutes \\
\hline Physical activity together in car & $\begin{array}{l}\text { 'How many hours and minutes per week do you sit in the car } \\
\text { TOGETHER with your child?' (parent) }\end{array}$ & $\ldots$ hours, ... minutes \\
\hline \multirow[t]{4}{*}{ Physical activity attitude } & $\begin{array}{l}\text { 'What do you think of exercise and physical activity for your child?' } \\
\text { (parent) }\end{array}$ & Summing up three items on a 3-point scale \\
\hline & - Importance & 1 = unimportant; 2 = important; 3 = very important \\
\hline & - Safety & 1 = dangerous $; 2$ = safe; 3 = very safe \\
\hline & - Health & $1=$ unhealthy $; 2=$ healthy; $3=$ very healthy \\
\hline
\end{tabular}


Table 1 Continued

\begin{tabular}{|c|c|c|}
\hline Physical activity modelling & $\begin{array}{l}\text { 'In an average week, how often do you do following activities?' (parent) } \\
\text { - Cycling } \\
\text { - Walking } \\
\text { - Exercise }\end{array}$ & $\begin{array}{l}\text { Summing up minutes spent in three activities } \\
\ldots \text { hours, } \ldots \text { minutes } \\
\ldots \text { hours, } \ldots \text { minutes } \\
\ldots \text { hours, } \ldots \text { minutes }\end{array}$ \\
\hline Physical activity together & 'How often do you exercise TOGETHER with your child?' (parent) & 4 -point scale $(1=$ never; $2=$ sometimes; $3=$ often; $4=$ always $)$ \\
\hline Physical activity logistic support & $\begin{array}{l}\text { 'How often do you bring your child to the place where he/she } \\
\text { exercises?' (parent) }\end{array}$ & 4-point scale $(1=$ never; $2=$ sometimes; $3=$ often; $4=$ always $)$ \\
\hline Physical activity encouragement & $\begin{array}{l}\text { 'How often do you watch or encourage your child while he/she } \\
\text { exercises?' (parent) }\end{array}$ & 4 -point scale $(1=$ never; 2 = sometimes; $3=$ often; $4=$ always $)$ \\
\hline $\begin{array}{l}\text { Physical activity benefits } \\
\text { Physical activity fitness benefit }\end{array}$ & $\begin{array}{l}\text { 'How important do you find following aspects of exercise?' (parent) } \\
\text { - Improving fitness and health }\end{array}$ & $\begin{array}{l}\text { 5-point scale }(1=\text { very unimportant; } 2=\text { unimportant; } 3=\text { don't know; } \\
\quad 4=\text { important; } 5=\text { very important })\end{array}$ \\
\hline Physical activity competition benefit & - Able to play competition and show that he/she is better than others & \\
\hline Physical activity social benefit & - Being together with friends and making new friends & \\
\hline Physical activity relaxing benefit & - Relaxing after a difficult school day & \\
\hline Physical activity fun benefit & - Having fun & \\
\hline Physical activity barriers & $\begin{array}{l}\text { 'What hinders your child to be physically active?' (parent) } \\
\text { - Lack of time } \\
\text { - Lack of perseverance } \\
\text { - Weak health, injuries } \\
\text { - Personal problems of your child (anxiety, etc.) } \\
\text { - Tot sporty } \\
\text { - Lack of sponsive (membership, clothing, equipment) } \\
\text { - Too large distance to sports facility } \\
\text { - Lack of transportation }\end{array}$ & $\begin{array}{l}\text { Mean value of ten items on a } 5 \text {-point scale }(1=\text { certainly not; } 2=\text { not; } \\
3=\text { don't know; } 4=\text { yes; } 5=\text { certainly yes })\end{array}$ \\
\hline School environmental predictor & Item (child questionnaire) & Response category \\
\hline \multicolumn{3}{|l|}{ Sociocultural (general) } \\
\hline Relation with classmates & $\begin{array}{l}\text { 'To what extent do you agree with following statements?' } \\
\text { - My classmates like being together } \\
\text { - Most classmates are friendly and helpful } \\
\text { - My classmates accept me as I am }\end{array}$ & $\begin{array}{l}\text { Mean value of three items on a } 5 \text {-point scale }(1=\text { totally not agree; } \\
2=\text { not agree; } 3=\text { no opinion; } 4=\text { agree; } 5=\text { totally agree })\end{array}$ \\
\hline Schoolwork stress & 'How pressured are you by the schoolwork you have to do?' (child) & 4-point scale $(1=$ not at all; $4=$ very much $)$ \\
\hline Good student according to teacher? & $\begin{array}{l}\text { 'What does your teacher think about your school results in comparison } \\
\text { to your classmates?' (child) }\end{array}$ & $\begin{array}{l}\text { 4-point scale }(1=\text { below; } 2 \text { = average student; } 3=\text { good student; } \\
4=\text { very good student })\end{array}$ \\
\hline \multicolumn{3}{|c|}{ 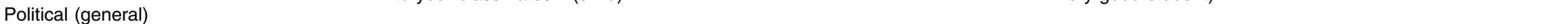 } \\
\hline Homework & $\begin{array}{l}\text { 'How many hours per day do you usually spend on making homework } \\
\text { and learning lessons, outside of school hours?' (child) }\end{array}$ & Hours per week + per weekend \\
\hline \multicolumn{3}{|l|}{ Physical (related to PA) } \\
\hline Activity in playtime & 'What do you usually do during recess and lunch break?' (child) & $1=$ sitting; $2=$ standing; $3=$ walking around; $4=$ sports \\
\hline
\end{tabular}


and validity (Spearman correlation $=0 \cdot 46$ ) to be useful for ranking subjects ${ }^{(30)}$. The questions to assess PA were derived from the reliable (intra-class correlation coefficient $>0 \cdot 60)$ and validated $(\kappa>0 \cdot 40)$ Flemish Physical Activity Questionnaire ${ }^{(31)}$ and have already been used in previous research assessing PA among adolescents ${ }^{(32,33)}$. To assess active transportation, minutes spent in active transportation to school and in leisure time were added up. Sports participation was created by adding up time spent in physical activities in leisure time (times per week multiplied by minutes per time). Finally, total PA was assessed by adding up time spent in active transportation, time spent in sports and hours of physical education at school.

\section{Family-and school-based predictors}

The child and parent questionnaire, completed at baseline in 2002, contained a wide range of questions related to children's health behaviour and well-being. For the current study, we only included family- and school-based variables that could be examined as a possible predictor of breakfast consumption, soft drink consumption and total PA level. In total, there were twenty-three family environmental variables (three general variables, one variable related to breakfast consumption, five variables related to soft drink consumption and fourteen variables related to total PA) and eight school environmental variables (four general variables and four variables related to total PA) that could be investigated as potential predictors. The EnRG framework ${ }^{(2)}$ was applied to categorize the predictors. Since the present study focused specifically on the family and school, only environmental factors were included, divided into family and school environmental factors. For a further classification of the variables, the types of environment according to the ANGELO framework - i.e. one of the key inputs for EnRG were used $^{(3)}$ : (i) the physical environment, referring to the availability and accessibility of behavioural choices; (ii) the sociocultural environment, referring to what is socially appropriate, acceptable or desirable as related to the behavioural choices; (iii) the economic environment, referring to the 'affordability' of the behavioural choices; and (iv) the political environment, referring to rules and regulations regarding the behavioural choices. An overview of the family and school environmental variables with their response scales is given in Table 1.

\section{Statistical analyses}

Analyses were conducted using the SPSS statistical software package version $15 \cdot 0$. First, to examine the possible family- and school-based predictors of breakfast consumption, soft drink consumption and PA, single linear regressions were conducted for every family- and schoolbased variable per behaviour. All variables were treated as continuous variables. Variables that were significant in the single linear regressions were entered in a multiple 
linear regression model, after controlling for multicollinearity $(r>0 \cdot 60$, only the predictor with the highest bivariate correlation with the behaviour was included). In total, there were three multiple linear regression models, one model per behaviour.

Second, to check for moderating effects of gender and SES on the association between the family and school environmental predictors and the behaviour, the crossproduct terms of the possible moderator and predictors were entered in a hierarchical regression (step 3), after the main effects of the possible moderator (step 1) and of the predictor (step 2). To avoid high correlations between the main effects and the interaction terms, centred variables were used (raw data minus mean data). $P<0.05$ was considered significant.

\section{Results}

\section{Study sample}

The study sample consisted of 727 children $(51.9 \%$ girls, $99 \%$ Belgian nationality and $51.9 \%$ high SES as defined by parental education). Mean age of the sample of 2002 was $9 \cdot 9$ (SD 0.4) years with a mean BMI of $16 \cdot 5(\mathrm{SD} 2 \cdot 3) \mathrm{kg} / \mathrm{m}^{2}$. Drop-out analyses were conducted to look at baseline differences between the 727 children included and those who dropped out ( $n$ 987). No differences were found for gender, nationality, involvement in sports, active transportation, eating breakfast on weekdays or weekend days and consumption of soft drinks. The children who dropped out were somewhat older $(P=0 \cdot 01)$, had a somewhat higher BMI $(P=0 \cdot 03)$ and were less likely to have parent(s) with a higher education $(P<0 \cdot 001)$. Mean age of the 2008 sample was $16 \cdot 0(\mathrm{SD} 0 \cdot 4)$ years (range $15-17$ years) with a mean BMI of $20 \cdot 4(\mathrm{sD} 2 \cdot 6) \mathrm{kg} / \mathrm{m}^{2}$. Mean levels of breakfast consumption, soft drink consumption and PA in 2008 are reported in Table 2. Descriptive results for all family- and school-based predictors are provided in Supplementary Materials, Table A.

Table 2 Mean values of the energy balance-related behaviours at age 16 years among Flemish children $(n 727)$

\begin{tabular}{lr}
\hline Energy balance-related behaviour & \\
\hline Breakfast consumption (d/week) & \\
Mean & $6 \cdot 02$ \\
SD & $1 \cdot 8$ \\
Soft drink consumption (\%) & $9 \cdot 6$ \\
Never & $20 \cdot 0$ \\
$<1 \mathrm{~d} /$ week or seldom & $14 \cdot 6$ \\
1 d/week & $19 \cdot 0$ \\
$2-4$ d/week & $8 \cdot 5$ \\
5-6 d/week & $11 \cdot 2$ \\
Every day & $17 \cdot 2$ \\
Every day, more than once daily & $73 \cdot 0$ \\
Total PA level (min/d) & $43 \cdot 4$ \\
Mean & \\
SD &
\end{tabular}

PA, physical activity.

\section{Family and school environmental predictors of energy balance-related bebaviours}

We only present the results from the multiple linear regression analyses. Results from the single linear regression analyses can be consulted in Supplementary Materials, Table B.

\section{Family and school environmental predictors of breakfast consumption}

Three family environmental variables and two school environmental variables were studied (see Table 3). All variables together explained $6.7 \%$ of the variance in frequency of breakfast consumption at age 16 years $(F=10 \cdot 93, \quad P<0 \cdot 001)$. One significant family environmental predictor was identified. Having breakfast together with the parents at the age of 10 years was significantly associated with eating breakfast on more days of the week at the age of 16 years $(P<0 \cdot 001)$. No significant school environmental variables were identified for breakfast consumption. Gender and SES did not significantly moderate the associations between these predictors and the frequency of breakfast consumption.

\section{Family and school environmental predictors of soft drink consumption}

Six family environmental variables and one school environmental variables were studied for soft drink consumption (see Table 3). All variables together explained $18 \cdot 2 \%$ of the variance in soft drink consumption at age 16 years $(F=17 \cdot 93, P<0 \cdot 001)$. Four significant family environmental predictors were identified. More availability of soft drinks at home at age 10 years was related to more soft drink consumption at age 16 years $(P<0 \cdot 001)$. A higher parental consumption of soft drinks at age 10 years was related to more soft drink consumption at age 16 years $(P=0 \cdot 04)$. Finally, children who received soft drinks from their parents whenever they asked for it at age 10 years, and children who could take soft drinks whenever they wanted at age 10 years, consumed more soft drinks at age 16 years $(P=0.02$ and $P=0 \cdot 001$, respectively). Availability of soft drinks at home was the strongest predictor with a $\beta$ value of $0 \cdot 23$. There were no significant school environmental predictors of soft drink consumption. Gender and SES did not significantly moderate the associations between these predictors and soft drink consumption.

\section{Family and school environmental predictors of physical activity}

Five family environmental variables and three school environmental variables were studied (see Table 3 ). All variables together explained $9.8 \%$ of the variance in the total PA level at age 16 years $(F=9 \cdot 48, P<0 \cdot 001)$. Three significant family environmental predictors were identified. A more positive parental attitude towards PA at the age of 10 years was significantly related to more PA at age 
Table 3 Family and school environmental predictors of breakfast consumption, soft drink consumption and total PA at age 16 years among Flemish children $(n$ 727)

\begin{tabular}{|c|c|c|c|c|c|}
\hline Dependent variable & Independent variables & $\beta$ & $t$ & $P$ & Adj $R^{2}$ \\
\hline \multirow[t]{8}{*}{ Breakfast at age 16 years (d/week) } & Full model $(F=10 \cdot 93)$ & & & $<0.001$ & 0.067 \\
\hline & Sociocultural & & & & \\
\hline & Good student according to parent? & 0.05 & $1 \cdot 26$ & NS & \\
\hline & BMI parent & -0.07 & -1.94 & NS & \\
\hline & Breakfast together & 0.22 & $5 \cdot 93$ & $<0.001$ & \\
\hline & $\begin{array}{l}\text { Soclocultural } \\
\text { Good student according to teacher? }\end{array}$ & 0.06 & $1 \cdot 50$ & NS & \\
\hline & Political & & & & \\
\hline & Homework & -0.07 & $-1 \cdot 89$ & NS & \\
\hline \multirow[t]{12}{*}{ Soft drink consumption at age 16 years ( $\mathrm{d} /$ week) } & Full model $(F=22 \cdot 90)$ & & & $<0.001$ & $0 \cdot 182$ \\
\hline & $\begin{array}{l}\text { Family environment } \\
\text { Physical }\end{array}$ & & & & \\
\hline & Availability at home & $0 \cdot 23$ & $6 \cdot 15$ & $<0.001$ & \\
\hline & Sociocultural & & & & \\
\hline & Good student according to parent? & -0.04 & $-1 \cdot 01$ & NS & \\
\hline & $\begin{array}{l}\text { Soft drink consumption parents } \\
\text { Political }\end{array}$ & 0.08 & $2 \cdot 09$ & $0 \cdot 04$ & \\
\hline & Soft drink consumption parenting 1 & 0.04 & $1 \cdot 06$ & NS & \\
\hline & Soft drink consumption parenting 2 & $-0 \cdot 10$ & $-2 \cdot 39$ & 0.02 & \\
\hline & Soft drink consumption parenting 3 & -0.20 & $-4 \cdot 66$ & $<0.001$ & \\
\hline & School environment & & & & \\
\hline & Sociocultural & & & & \\
\hline & Good student according to teacher? & -0.07 & $-1 \cdot 80$ & NS & \\
\hline \multirow[t]{12}{*}{ Total PA at age 16 years $(\mathrm{min} / \mathrm{d})$} & Full model $(F=9 \cdot 48)$ & & & $<0.001$ & 0.098 \\
\hline & $\begin{array}{l}\text { Family environment } \\
\text { Sociocultural }\end{array}$ & & & & \\
\hline & PA attitude & $0 \cdot 11$ & $2 \cdot 63$ & 0.009 & \\
\hline & PA encouragement & $0 \cdot 17$ & 3.08 & 0.002 & \\
\hline & PA fun benefit & -0.06 & $-1 \cdot 42$ & NS & \\
\hline & PA relaxing benefit & $0 \cdot 17$ & $3 \cdot 73$ & $<0.001$ & \\
\hline & PA logistic support & -0.03 & $-0 \cdot 47$ & NS & \\
\hline & $\begin{array}{l}\text { School environment } \\
\text { Physical }\end{array}$ & & & & \\
\hline & Activity in playtime & 0.01 & $0 \cdot 29$ & NS & \\
\hline & Participation extra-curricular sports & 0.07 & $1 \cdot 61$ & NS & \\
\hline & Political & & & & \\
\hline & Hours PE & 0.01 & $0 \cdot 29$ & NS & \\
\hline
\end{tabular}

PA, physical activity; PE, physical education.

16 years $(P=0 \cdot 009)$. More parental encouragement at the age of 10 years was significantly related to more PA at the age of 16 years $(P=0 \cdot 002)$. A higher parental rating of PA's benefit 'relaxing after school' was related to more $\mathrm{PA}$ at age 16 years $(P<0 \cdot 001)$. The strongest predictor was the rating of PA's benefit 'relaxing after school' with a $\beta$ value of $0 \cdot 17$. No significant school environmental predictors were identified for PA. Gender and SES did not significantly moderate the associations between these predictors and total PA.

\section{Discussion}

The current study, exploring longitudinal associations between the family and school environment and three EBRB among Flemish schoolchildren with a 6-year follow-up, provides further evidence for the major role of parents in influencing children's health behaviours, which is in line with a recent systematic review ${ }^{(13)}$. Regarding the frequency of breakfast consumption, one significant family environmental predictor was found, namely having breakfast together with the parents at the age of 10 years. A review of family correlates of breakfast consumption in children ${ }^{(34)}$ already concluded that parental breakfast eating was positively associated with breakfast consumption in children, but our results add that it is important for parents to eat that breakfast together with their children to have an impact on future breakfast consumption. Parents act as a role model for their children and breakfast consumption might become a routine then for children, resulting in more days of eating breakfast at an older age.

For soft drink consumption, a number of family environmental predictors were revealed. Availability of soft drinks at home was the strongest family environmental 
predictor. Given that parents are the primary gatekeepers of purchases at home ${ }^{(35)}$, parents could restrict the availability of soft drinks and, as a consequence, have an impact on the soft drink consumption of their children. Further, parents should avoid using a permissive parenting style, since two indicators of permissiveness were related to more soft drink consumption. Previous studies have found as well that a permissive parenting style had pernicious consequences in the long term for the intake of unhealthy foods in children ${ }^{(36,37)}$. In contrast, some studies suggested that a strict parental control or an authoritarian parenting style could also lead to the development of unhealthy behaviours ${ }^{(38,39)}$. As both parenting styles seem to be inversely associated with healthy behaviour, it is recommended for parents to adopt a more authoritative parenting style to promote healthy behaviours among children. This parenting style represents a balance between an authoritarian and a permissive parenting style and is characterized by encouraging children to perform healthy behaviour and offering them choices rather than forcing them or leaving the child to his or her own devices ${ }^{(35)}$. Finally, the positive association between parental soft drink consumption at the age of 10 years and children's soft drink consumption at the age of 16 years confirmed the positive role model function of parents. It has been suggested that parents who regularly consume soft drinks are less likely to have rules regarding their children's soft drink consumption ${ }^{(40)}$. The findings of the present study regarding predictors of soft drink consumption are all in line with the findings of our previous review, although these were based on solely cross-sectional studies ${ }^{(13)}$. Thus, the longitudinal results of the current study contribute to the cross-sectional evidence found in the review.

Our findings showed that a higher parental rating of PA's benefit 'relaxing after school' at age 10 years was the strongest predictor of PA at age 16 years. A possible explanation for this significant relationship is that if parents perceive relaxing after school by means of PA as important, they are more apt to stimulate their children to be physically active after school. Further, parental encouragement at the age of 10 years predicted PA at the age of 16 years as well. This finding is not in line with the results of the review where parental encouragement was found to show mixed associations with children's $\mathrm{PA}^{(13)}$. However, the great majority of the included studies were cross-sectional and the studies that used a longitudinal design did find a positive association ${ }^{(41,42)}$. It has been suggested that parental encouragement, a form of emotional parental support, could affect children's PA behaviour in a direct way as well as in an indirect way, because of its influence on self-efficacy ${ }^{(23,43,44)}$ and on competence ${ }^{(45)}$. Moreover, it has been stated that parental encouragement could mediate the relationship between parental and child activity ${ }^{(46)}$. These different manners of influencing children's PA might implicate a significant role for parental encouragement.
As mentioned in the introduction to the present paper, it is known that at the ages of 10-12 years, parents (and not peers) have the most impact on children's behaviour. When children reach an older age, it has been stated that peer influences become more important than parental influences ${ }^{(47)}$. However, the current study results suggest that parental factors at the age of 10 years associate with adolescents' behaviour at age 16 years. Consequently, an obesity prevention programme with a strong focus on the identified parental predictors at age 10 years might have positive effects on children's behaviour in the long term.

No significant relationships were found between primary school environmental variables and future breakfast and soft drink consumption. Thus, the family environment appears to be of more importance in predicting breakfast and soft drink consumption, which is in line with the findings of the review of de Vet et al. ${ }^{(48)}$. Another possible explanation could be that the investigated school environmental variables were not sufficiently behaviourspecific (e.g. relation with classmates). For PA, it has been advocated that as physical activities often occur outside the home, other environments such as the school environment might be of greater importance than the family environment ${ }^{(48)}$. The present study results do not support this hypothesis, as no school environmental factors significantly predicted PA at age 16 years. Although there were some PA-specific school environmental variables available to investigate (e.g. hours of physical education lessons), the low variance within the school environmental variables could be partly responsible for the non-significant results for PA. It may be that the change in school environment from baseline to follow-up (i.e. primary to secondary school) is responsible for the fact that school environmental factors were poor predictors of adolescents' EBRB.

To sum up, several family environmental factors should be taken into account when developing an obesity prevention programme. Based on all significant study results, the following recommendations can be made: to have a positive impact upon EBRB in later adolescence, parents of 10-year-olds should be encouraged to have breakfast together with their children, to restrict their children's and their own intake of soft drinks, to reduce soft drink availability at home, to encourage their children during activities, to develop a positive attitude towards PA and to consider PA as an excellent way of relaxing after a long school day. These predictors applied to both boys and girls and to children from low-SES and high-SES families, suggesting that an intervention programme focusing on these predictors does not have to specifically pay attention to a subgroup of children.

There are some limitations that need to be acknowledged. A first limitation is the use of the self-report measures by children and parents which could have led to socially desirable answers. Further, we have used brief scales to report the complex EBRB, although they have 
been proven sufficiently reliable and valid ${ }^{(30)}$. A second limitation is the relatively large drop-out which could have consequences for the generalizability of the results. However, drop-out analyses did indicate that drop-out may not have been that selective and the study still had a relatively large study sample with 727 children. Inherent to secondary data analyses, a final limitation of the study is that we were only able to include the family and school environmental variables that were at our disposal in the baseline questionnaire. As a result, a larger number of variables related to PA could be investigated, suggesting further research is needed to gain more insight into the predictors of the dietary behaviours, particularly breakfast consumption. Moreover, future research should investigate more behaviour-specific school environmental variables, as this was not the case in the present study. Finally, most variables were situated in the sociocultural domain and although the sociocultural environment appeared to be the most important one to predict future EBRB, future research should investigate variables in other domains as well. An important strength of the current study is the 6-year follow-up period going from childhood to adolescence which is unique for a European study examining several family- and school-based predictors.

\section{Conclusions}

The current study shows that several family environmental factors at age 10 years predicted breakfast consumption, soft drink consumption and PA at age 16 years. No school environmental predictors were identified. An obesity prevention programme in the final years of primary school focusing on the significant parental factors might lead to healthy behaviour in adolescence.

\section{Acknowledgements}

Source of funding: The ENERGY project is funded by the Seventh Framework Programme (CORDIS FP7) of the European Commission, HEALTH (FP7-HEALTH-2007-B), Grant Agreement no. 223254. The contents of this article reflect the authors' views only and the European Community is not liable for any use that may be made of the information contained herein. Conflicts of interest: The authors declare that they have no competing interests. Authors' contribution: J.B. developed the concept and design of the ENERGY project. L.M. and I.D.B. provided the data set. M.V. conducted the secondary analyses with help from W.V.L., L.M. and I.D.B.M.V. wrote the first draft of the paper. All authors read and approved the final manuscript.

\section{Supplementary Materials}

For Supplementary Materials for this article, please visit http://dx.doi.org/10.1017/S1368980012004120.

\section{References}

1. Brug J, Oenema A \& Ferreira I (2005) Theory, evidence and Intervention Mapping to improve behavior nutrition and physical activity interventions. Int J Behav Nutr Phys Act 2, 2.

2. Kremers SPJ, de Bruijn GJ, Visscher TLS et al. (2006) Environmental influences on energy balance-related behaviors: a dual-process view. Int J Behav Nutr Phys Act 3, 9.

3. Swinburn B, Egger G \& Raza F (1999) Dissecting obesogenic environments: the development and application of a framework for identifying and prioritizing environmental interventions for obesity. Prev Med 29, 563-570.

4. Ajzen I (1991) The theory of planned behavior. Organ Behav Hum Decis Process 50, 179-211.

5. Edwardson CL \& Gorely T (2010) Parental influences on different types and intensities of physical activity in youth: a systematic review. Psychol Sport Exerc 11, 522-535.

6. Gross SM, Pollock ED \& Braun B (2010) Family influence: key to fruit and vegetable consumption among fourth- and fifth-grade students. J Nutr Educ Behav 42, 235-241.

7. Brug J, te Velde SJ, Chinapaw MJM et al. (2010) Evidencebased development of school-based and family-involved prevention of overweight across Europe: the ENERGYproject's design and conceptual framework. BMC Public Health 10, 276.

8. Golley RK, Hendrie GA, Slater A et al. (2011) Interventions that involve parents to improve children's weight-related nutrition intake and activity patterns - what nutrition and activity targets and behaviour change techniques are associated with intervention effectiveness? Obes Rev 12, 114-130.

9. De Bourdeaudhuij I, Van Cauwenberghe E, Spittaels H et al. (2011) School-based interventions promoting both physical activity and healthy eating in Europe: a systematic review within the HOPE project. Obes Rev 12, 205-216.

10. Gillander Gådin K \& Hammarström A (2002) Can schoolrelated factors predict future health behaviour among young adolescents? Public Health 116, 22-29.

11. Story M, Kaphingst KM \& French S (2006) The role of schools in obesity prevention. Future Child 16, 109-142.

12. Wechsler H, Devereaux RS, Davis M et al. (2000) Using the school environment to promote physical activity and healthy eating. Prev Med 31, Suppl., S121-S137.

13. Verloigne M, Van Lippevelde W, Maes L et al. (2012) Family- and school-based correlates of energy balancerelated behaviours in 10-12-year-old children: a systematic review within the ENERGY (EuropeaN Energy balance Research to prevent excessive weight Gain among Youth) project. Public Health Nutr 15, 1380-1395.

14. Golan M \& Crow S (2004) Parents are key players in the prevention and treatment of weight-related problems. Nutr Rev 62, 39-50.

15. Van Lenthe FJ, Boreham CA, Twisk JWR et al. (2001) Socioeconomic position and coronary heart disease risk factors in youth - findings from the Young Hearts Project in Northern Ireland. Eur J Public Health 11, 43-50.

16. Bois JE, Sarrazin PG, Brustad RJ et al. (2005) Elementary schoolchildren's perceived competence and physical activity involvement: the influences of parents' role modelling behaviours and perceptions of their child's competence. Psychol Sport Exerc 6, 381-397.

17. Branca F, Nikogosian H \& Lobstein T (2007) The Challenge of Obesity in the WHO European Region and the Strategies for Response. Copenhagen: WHO Regional Office for Europe.

18. Moreno LA, Rodriguez G, Fleta J et al. (2010) Trends in dietary habits in adolescents. Crit Rev Food Sci Nutr 50, 106-112.

19. Bachman CM, Baranowski T \& Nicklas TA (2006) Is there an association between sweetened beverages and adiposity? Nutr Rev 64, 153-174. 
20. Clabaugh K \& Neuberger GB (2011) Research evidence for reducing sweetened beverages in children. Issues Compr Pediatr Nurs 34, 119-130.

21. Malik VS, Schulze MB \& Hu FB (2006) Intake of sugarsweetened beverages and weight gain: a systematic review. Am J Clin Nutr 84, 274-288.

22. Jiménez-Pavon D, Kelly J \& Reilly JJ (2010) Associations between objectively measured habitual physical activity and adiposity in children and adolescents: systematic review. Int J Pediatr Obes 5, 3-18.

23. Brug J, van Stralen MM, te Velde SJ et al. (2012) Differences in weight status and energy-balance related behaviors among schoolchildren across Europe: the ENERGY-project. Plos One 7, e34742.

24. Barnett TA, O'Loughlin J \& Paradis G (2002) One- and two-year predictors of decline in physical activity among inner-city schoolchildren. Am J Prev Med 23, 121-128.

25. Crawford D, Cleland V, Timperio A et al. (2010) The longitudinal influence of home and neighbourhood environments on children's body mass index and physical activity over 5 years: the CLAN study. Int J Obes (Lond) $\mathbf{3 4}$, $1177-1187$.

26. Sallis JF, Alcaraz JE, McKenzie TL et al. (1999) Predictors of change in children's physical activity over 20 months variations by gender and level of adiposity. Am J Prev Med 16, 222-229.

27. Salmon J, Timperio A, Telford A et al. (2005) Association of family environment with children's television viewing and with low level of physical activity. Obes Res 13, 1939-1951.

28. Mutunga M, Gallagher AM, Boreham C et al. (2006) Socioeconomic differences in risk factors for obesity in adolescents in North Ireland. Int J Pediatr Obes 1, 114-119.

29. Haerens L, Vereecken C, Maes L et al. (2010) Relationship of physical activity and dietary habits with BMI in the transition from childhood to adolescence: a 4-year longitudinal study. Public Health Nutr 13, 1722-1728.

30. Vereecken C \& Maes L (2003) A Belgian study on the reliability and relative validity of the Health Behaviour in School-aged Children food-frequency questionnaire. Public Health Nutr 6, 581-588.

31. Philippaerts RM, Matton L, Wijndaele K et al. (2006) Validity of a physical activity computer questionnaire in 12- to 18-year-old boys and girls. Int J Sports Med 27, 131-136.

32. Haerens L, De Bourdeaudhuij I, Maes L et al. (2007) School-based randomized controlled trial of a physical activity intervention among adolescents. $J$ Adolesc Health 40, 258-265.

33. Haerens L, Deforche B, Maes L et al. (2007) Physical activity and endurance in normal weight versus overweight boys and girls. J Sports Med Phys Fitness 47, 344-350.
34. Pearson N, Biddle SJH \& Gorely T (2009) Family correlates of breakfast consumption among children and adolescents. Appetite 52, 1-7.

35. Patrick H \& Nicklas TA (2005) A review of family and social determinants of children's eating patterns and diet quality. J Am Coll Nutr 24, 83-92.

36. De Bourdeaudhuij I (1997) Family food rules and healthy eating in adolescents. $J$ Health Psychol 2, 45-56.

37. Vereecken C, Haerens L, De Bourdeaudhuij I et al. (2010) The relationship between children's home food environment and dietary patterns in childhood and adolescence. Public Health Nutr 13, 1729-1735.

38. Carper JL, Orlet FJ \& Birch LL (2000) Young girls' emerging dietary restraint and disinhibition are related to parental control in child feeding. Appetite 35, 121-129.

39. Fisher JO, Mitchell DC, Smiciklas-Wright H et al. (2002) Parental influences on young girls' fruit and vegetable, micronutrient, and fat intakes. I Am Diet Assoc 102, 58-64.

40. Grimm GC, Harnack L \& Story M (2004) Factors associated with soft drink consumption in school-aged children. $J \mathrm{Am}$ Diet Assoc 104, 1244-1249.

41. Cleland V, Dwyer T, Blizzard L et al. (2008) The provision of compulsory school physical activity: associations with physical activity, fitness and overweight in childhood and twenty years later. Int J Behav Nutr Phys Act 5, 14

42. Sallis JF, Alcaraz JE, McKenzie TL et al. (1999) Predictors of change in children's physical activity over 20 months variations by gender and level of adiposity. Am J Prev Med 16, 222-229.

43. DiLorenzo TM, Stucky-Ropp RC, Van der Wal JS et al. (1998) Determinants of exercise among children. II. A longitudinal analysis. Prev Med 27, 470-477.

44. Dzewaltowski DA, Karteroliotis K, Welk G et al. (2007) Measurement of self-efficacy and proxy efficacy for middle school youth physical activity. J Sport Exerc Psychol 29, 310-332.

45. Biddle S \& Goudas M (1996) Analysis of children's physical activity and its association with adult encouragement and social cognitive variables. $J$ Sch Health 66, 75-78.

46. Gustafson SL \& Rhodes RE (2006) Parental correlates of physical activity in children and early adolescents. Sports Med 36, 79-97.

47. Duncan SC, Duncan TE \& Strycker LA (2005) Sources and types of social support in youth physical activity. Health Psychol 24, 3-10.

48. de Vet E, de Ridder DTD \& de Wit JBF (2011) Environmental correlates of physical activity and dietary behaviours among young people: a systematic review of reviews. Obes Rev 12, e130-e142. 